\title{
Saltarse el programa: revolución y viaje en las memorias de tres autoras latinoamericanas
}

\section{Off the Beaten Path: Revolution and Travel in Memoirs by Three Latin American Women Authors}

\author{
Liliana Guadalupe Chávez Díaz ${ }^{1}$ \\ Universidad Autónoma Metropolitana, México \\ lilianachavez@azc.uam.mx
}

\begin{abstract}
Resumen: En este artículo se reflexiona sobre memorias escritas por autoras latinoamericanas y la narrativa de viajes contemporánea. Se inscribe en el debate en torno a la memoria y la literatura del yo en la literatura latinoamericana publicada a partir del 2000, a través del análisis de testimonios de viaje de mujeres escritos en primera persona en el contexto de las guerrillas y revoluciones de los años sesenta. El objetivo es identificar los usos particulares del lenguaje que las autoras latinoamericanas desarrollaron para autorrepresentarse mientras viajaban por un territorio aún en desarrollo y que enfrentaba grandes cambios sociales. El estudio se centra en El país bajo mi piel (200I), de Gioconda Belli; La Habana en un espejo (2004), de Alma Guillermoprieto, y Viajes: De la
\end{abstract}

${ }^{1}$ Este artículo se deriva del proyecto de investigación "Viajar Sola: autorrepresentación y experiencia en narrativas de no ficción de mujeres hispanoamericanas", que la autora desarrolló durante una estancia postdoctoral en la UAMAzcapotzalco, financiada por CONACYT, de agosto de 2018 a julio de 2020. 
Amazonía a las Malvinas (20 I4), de Beatriz Sarlo. Se propone aportar al conocimiento de la narrativa de no ficción latinoamericana y de autoras poco atendidas por la crítica literaria mediante el estudio de la literatura de viaje como medio de expresión de la memoria individual y colectiva. El artículo ofrece una perspectiva femenina en torno a la relación entre ideología, política y viaje, al mismo tiempo que explora las representaciones de clase y género en la literatura contemporánea.

Palabras clave: memorias latinoamericanas, crónicas de viaje de mujeres, Gioconda Belli, Alma Guillermoprieto, Beatriz Sarlo.

Abstract: This paper reflects on memoirs and travel writing by Latin American women authors. It intends to contribute to the discussion regarding memory and self-representation within the field of Latin American literature that has been publishing since 2000, by focusing on female first-person travel accounts about guerrillas and revolutions during the I96os. The aim is to trace the particular uses of language that women writers have developed in Latin America to represent themselves while traveling on their own, across a continent under development and facing great social challenges. The main focus is on The Country Under My Skyn: A memoir of love and war (El pais bajo mi piel, 200I), by Gioconda Belli; Dancing with Cuba (La Habana en un espejo, 2004), by Alma Guillermoprieto, and Viajes: De la Amazonia a las Malvinas (2014), by Beatriz Sarlo. I propose to shed light into Latin American nonfiction and lesser known female authors, studying travel literature as a means of individual and collective expression of memory. The paper offers a female perspective on ideology, politics and travel, while raising awareness of class and gender representations in contemporary literature.

Keywords: Latin American memoirs, Female travel writing, Gioconda Belli, Alma Guillermoprieto, Beatriz Sarlo. 
Recibido: 7 de mayo de 2020

Aceptado: ro de septiembre de 2020 https://dx.doi.org/I O.I 5 I 74/rv.vi 3i27.547

$\mathrm{E}^{\mathrm{n}}$ n la crónica de su viaje por la península de Yucatán, el escritor mexicano Juan Villoro (1989) se autorrepresenta sentado en un café en los portales de Mérida, libreta en mano, cuando de pronto lo sorprende una escena frente a él: en otra mesa hay una mujer que también bebe café, también escribe en una libreta y también está sola. Juzgando la apariencia de la mujer y su situación en el contexto cultural que la rodea, Villoro intuye que es una viajera de tipo "mochilera" y que quizá sea extranjera. En un país donde las mujeres no pueden ir solas ni al baño, reflexiona Villoro, es aún más raro que una se atreva a viajar sola.

Si bien la literatura de viajes no ha sido particularmente un género de interés para los escritores y críticos latinoamericanos (Lindsay, 2010), el auge que el género de la crónica ha tenido en la región desde finales del siglo $\mathrm{xx}$ ha renovado el interés por las experiencias de viaje relatadas en primera persona. ${ }^{2}$ Del lado de los autores masculinos, se puede trazar una genealogía que va des-

${ }^{2}$ Este auge se inicia simbólicamente con la creación en 1995 de la Fundación para un Nuevo Periodismo Iberoamericano, dirigida originalmente por Gabriel García Márquez y renombrada Fundación Gabo después de su muerte. Esta fundación ha fomentado encuentros de escritores autodenominados "Nuevos cronistas de Indias" y financiado talleres de escritura para periodistas, así como publicaciones de manuales e investigaciones sobre el tema, entre ellos un estudio pionero sobre la crónica modernista La invención de la crónica, de Susana Rotker, así como antologías derivadas de un premio anual internacional también organizado por esta institución. En el terreno editorial, el boom de la crónica se puede observar en la publicación de colecciones editadas por académicos como la Antología de crónica latinoamericana actual (2012), de Darío Jaramillo Agudelo; Mejor que ficción: crónicas ejemplares (2012), de Jorge Carrión, y Crónica y mirada. Aproximaciones al periodismo narrativo (2013), de María Angulo Egea. 
de los cronistas de Indias, como Cristóbal Colón y Álvar Núñez Cabeza de Vaca, hasta los proclamados por el gremio periodísticoliterario como "nuevos cronistas", con Martín Caparrós y Juan Villoro al frente. Sin embargo, las mujeres latinoamericanas que viajan y escriben sobre su experiencia siguen siendo excepciones. Desde la primera antología de crónica de Carlos Monsiváis en 1980 hasta las más recientes (Angulo, 2013; Carrión, 2012; Jaramillo, 2012), los nombres femeninos que se incluyen son pocos y se repiten, como Elena Poniatowska, Leila Guerriero, Magali Tercero y Gabriela Wiener. Menos aún son los ejemplos de crónicas específicamente de viajes firmadas por mujeres. Esto quizá se deba a que la condición de libertad que exige este tipo de producción textual no es compatible con la cultura misógina y conservadora que históricamente ha impedido el desplazamiento libre y seguro de las mujeres. Me parece que esto ha dificultado la incorporación de autoras latinoamericanas al canon del género "literatura de viajes", al menos en el sentido que el término tiene para la tradición literaria occidental.

Otro problema ineludible al elegir este tema es la naturaleza híbrida del corpus elegido. Según la disciplina o perspectiva teórica desde la cual se aborden los géneros, podría considerarse a la crónica como un subgénero de la literatura de viajes o como un género entre cuyos subgéneros se encuentra la crónica de viajes. Las obras que me ocupan en este artículo podrían leerse tanto como crónicas, relatos o literatura de viajes o, siguiendo una clasificación internacional, como travel writing. Considerando que el corpus tratado se ubica también bajo el género de "memorias", en este artículo utilizo indistintamente los términos "crónica" y "relato" para referirme a textos de no ficción en que las autoras recuerdan, describen y narran, con apoyo en evidencia documental y con consciencia autoral, sus desplazamientos físicos por América Latina. 
Desde una perspectiva narratológica aplicada a textos hispánicos del siglo x al xv, Carrizo Rueda (1997) propuso una teoría morfológica del género del relato de viajes con el fin de distinguir los libros de viajes de otros géneros "duales" (entre lo documental y lo literario), como las crónicas o las biografías históricas. Si bien reconozco la utilidad de este tipo de propuestas para valorar lo literario en géneros híbridos tradicionalmente relegados por la crítica literaria hispánica, en este artículo propongo un acercamiento interdisciplinario alternativo para la narrativa latinoamericana contemporánea que tematiza el viaje. Lo anterior porque lo que me interesa aquí no es discutir la "literaturidad" o especificidad literaria de las obras, ni tampoco los límites formales entre los diversos géneros que suelen tratar los viajes como motivo o tema, sino algo más modesto: identificar las relaciones que ciertos textos híbridos, escritos por mujeres, sobre y desde América Latina, plantean entre la experiencia viajera, escritura e identidad en la actualidad. Concebir entonces, como propone Carrizo Rueda con base en un corpus español medieval, el relato de viajes como "un discurso narrativo-descriptivo en el que predomina la función descriptiva como consecuencia del objeto final, que es la presentación del relato como un espectáculo imaginario, más importante que su desarrollo y su desenlace" (1997: 28) excluiría del género al corpus aquí tratado y a muchos otros textos contemporáneos que documentan el viaje.

A la luz de nuevas formas de vivir y relatar la experiencia viajera, sobre todo la femenina, me parece importante pensar también en nuevas formas de analizar la literatura de viajes en español que consideren los nuevos contextos globalizados de su producción, difusión y lectura. De esta manera, mi visión del género es más afín a la planteada por Guzmán Rubio siguiendo a Alburquerque y Peñate (2011), al considerar que el relato de viajes hispanoamericano contemporáneo posee una naturaleza maleable y tiene la po- 
sibilidad de "enquistarse" en otros géneros, como la autobiografía, las memorias, diarios, cartas y crónicas. Si bien podría discutirse la pertenencia o no de ciertos relatos de corte testimonial o biográfico al género de viajes, sí considero que una gran variedad de textos híbridos puede leerse como relatos de viaje, sobre todo en el caso de escrituras femeninas que exigen genealogías propias porque dialogan con tradiciones literarias diferentes al canon hispanoamericano masculino. Esta narrativa de viajes permite plantearse debates pertinentes, y urgentes, sobre las relaciones entre géneros literarios y géneros sexuales. Después de todo, en el caso del género de viajes, como concluye Guzmán Rubio, "estamos ante uno de los géneros literarios con mayor libertad y variedad formal" (2011: 128).

En este artículo intento demostrar que, si bien aún es necesaria una investigación interdisciplinaria más amplia y de carácter archivístico para rescatar una tradición latinoamericana de viajes femenina, es posible rastrear relatos de viajes en otros géneros narrativos, considerados privados o menores, que dan cuenta de viajes de mujeres, como correspondencia, diarios y memorias. Por lo tanto, este artículo propone una lectura de textos que no suelen presentarse como crónicas de viaje pero que pueden ser útiles para delinear una genealogía propia de la experiencia del viaje femenino latinoamericano, así como problematizar la autorrepresentación de las autoras en textos de no ficción, particularmente en el género de las memorias. Sostengo que, para las autoras latinoamericanas, documentar sus viajes, ya sea a través de textos públicos o privados, se convierte en un medio para ensayar formas de expresar ideas y afectos que a su vez ejemplifican procesos particulares de construcción de subjetividades.

Después de ofrecer un panorama general de la representación del viaje femenino latinoamericano, me enfocaré al análisis comparativo de algunos textos de no ficción, publicados en las pri- 
meras dos décadas del siglo XXI, que abordan recuentos de viajes realizados por las autoras durante su juventud en las décadas de las revoluciones socialistas en América Latina. Particularmente, se estudian los siguientes textos: Viajes: De la Amazonía a las Malvinas (2014), de la argentina Beatriz Sarlo; La Habana en un espejo (2004), de la mexicana Alma Guillermoprieto, y El pais bajo mi piel, memorias de amor y de guerra (2001), de la nicaragüense Gioconda Belli. Estas obras son actos de memoria en primera persona sobre los primeros viajes que realizaron mujeres latinoamericanas dentro y fuera de sus países durante el periodo que se ha denominado "the long sixties" (Strain, 2017), el cual estuvo marcado en América Latina por un contexto ideológico revolucionario y un despertar a nuevas subjetividades femeninas. ${ }^{3}$ Además, estas obras forman parte de un nuevo auge de la literatura testimonial latinoamericana y del fenómeno editorial de finales del siglo xx y principios del xxi en torno a las narrativas del yo. Finalmente, el estudio de estas obras también permite inscribir la historia de la escritura de viajes latinoamericana en el renovado interés de la crítica literaria internacional por este género literario desde la última década del siglo xx. ${ }^{4}$

${ }^{3}$ En su libro sobre la historia cultural de los sesenta, Strain distingue entre el periodo meramente histórico de la década de 1960 y un tiempo más amplio en el cual la sociedad occidental vivió grandes cambios de valores y paradigmas; considerando hechos que marcaron la vida estadounidense principalmente, para Strain este periodo abarcaría desde el fin de la Segunda Guerra Mundial y los primeros movimientos a favor de los derechos civiles de 1955 hasta el caso Watergate en 1973 (2017: VI-VII).

${ }^{4}$ Ver, por ejemplo, Imperial Eyes: Travel Writing and Transculturation (1992), de Mary Louise Pratt; Culture and Imperialism (1993), de Edward Said, y Tourist with Typewriters. Critical Reflections on Contemporary Travel Writing (1998), de Patrick Holland y Graham Huggan; en el campo hispánico y latinoamericano, ver Poética del relato de viajes (1997), de Sofía M. Carrizo Rueda; Viaje intelectual. Migraciones y desplazamientos en América Latina 1880-1915 (2004), de 


\section{Hacia una historia del viaje femenino por América Latina}

Si viajar ha sido históricamente una empresa masculina, no es sorprendente que la escritura de viajes también haya sido, hasta muy avanzado el siglo $\mathrm{xx}$, un género literario profundamente varonil, además de una práctica imperialista occidental (Pratt, 1992). En la nueva América, los cronistas de viajes solían ser por lo general hombres ligados a algún proyecto bélico o científico. Durante el siglo XIX y principios del xx, las mujeres estadounidenses y europeas que viajaban por América Latina normalmente lo hacían para seguir a sus esposos o, excepcionalmente, porque su profesión como educadoras o científicas se los exigía (Medeiros, 2019; Saunders, 2014). Por ejemplo, sobre viajes a México destacan las memorias $A$ Winter in Central America and Mexico (1889), de Helen Sanborn, o la más conocida colección epistolar Life in Mexico During a Residence of Two Years in That Country (1843), de Frances Calderón de la Barca. Se sabe aún menos sobre mujeres latinoamericanas viajeras en esta época, ya que estas vivían en sociedades todavía más conservadoras y los casos excepcionales se explican en parte por la doble nacionalidad o el contexto multicultural en el que se desenvolvían algunas autoras, como los viajes de la francesa de ascendencia peruana Flora Tristán y de la cubana Gertrudis Gómez de Avellaneda, que residió casi toda su vida en España (Hahner, 1998).

No es casual, además, que el registro de los viajes femeninos se realizara a través de la práctica de géneros discursivos privados o

Beatriz Colombi; Viaje contra espacio. Juan Goytisolo y W. G. Sebald (2009), de Jorge Carrión; Contemporary Travel Writing of Latin America (2010), de Claire Linsay; Viajes, desplazamientos e interacciones culturales en la literatura latinoamericana. De la conquista a la modernidad (2016), coordinado por Colombi, e Inmersiones. Crónicas de viajes y periodismo encubierto (2017), de María Angulo. 
"literatura menor", particularmente a través del género epistolar. En el siglo XIX, la popularización de la comunicación a través de cartas coincide con el inicio del turismo masivo, los movimientos feministas y una economía imperialista que inspiró e incluso auspició gran parte de la literatura de viajes (Earle, 2016; Pratt, 1992). A diferencia del viaje masculino, que se ha estudiado en relación al deseo de aventura y de expansión imperial, el viaje femenino se ha visto además como una forma de emancipación de las sociedades patriarcales.

La escritura femenina de viajes también ha compartido, como características fundacionales de este género literario, el afán etnográfico e imperialista con una visión eurocéntrica sobre los territorios visitados. No obstante, al representar a un sujeto viajero que interactúa de manera más compleja con las categorías de género, raza y clase, la escritura de mujeres viajeras ha destacado como vehículo que también permite el desplazamiento de normas patriarcales e imperiales (Holland y Huggan, 2000).

Si en el caso latinoamericano hay una escasa tradición de cronistas de viaje mujeres es quizá porque la experiencia de movilidad no solía hacerse pública. De Gertrudis Gómez de Avellaneda a Gabriela Mistral y Rosario Castellanos, pasando por Antonieta Rivas Mercado, Alejandra Pizarnik, Clarice Lispector y muchas más, la carta privada fue el género elegido por las mujeres latinoamericanas del siglo xIx y hasta la mitad del xx para registrar y compartir el viaje. Aunque eventualmente sus intercambios epistolares han llegado a hacerse públicos, este tipo de relatos eran originalmente creados desde y para la esfera privada. Entre estas pioneras del relato de viajes en nuestra región y las autoras contemporáneas que ya sin reparos pudieron asumir el oficio de cronistas de viajes profesionales -como Margo Glantz, María Moreno, Gabriela Wiener, Leila Guerriero o Valeria Luiselli- las memorias de viaje ofrecen un punto intermedio e híbrido en varios sentidos. Con base en 
otros documentos privados como la carta y el diario, las memorias mezclan en su registro una gran variedad de géneros discursivos para dar testimonio de una experiencia real, individual y colectiva, del pasado de sus autoras.

\section{El otro Grand Tour}

Según relata en Memorias de España 1937, Elena Garro salió una noche a recorrer el barrio chino de Barcelona con una amiga, cuando unas mujeres las detuvieron: “¿Tenéis carnet', nos preguntaron unas mujeres a Lolita y a mí? 'No... ¿de qué?', pregunté. 'De puta'" (2011: 48). Era el primer viaje de Garro a España. Tenía 20 años y recién se había casado con el poeta Octavio Paz para así poder asistir como su acompañante al iı Congreso Internacional de Escritores Antifascistas que se desarrolló en Valencia, Madrid y Barcelona en 1937.

Como se puede apreciar en el pasaje citado, el cuerpo femenino juega un papel significativo para la experiencia de viaje de la narradora. Su libre deambular por lugares poco comunes para mujeres suscita sospechas puesto que con su acción turística la narradora expone una fractura entre el sujeto femenino convencional y el que ellas están representando al salir a la calle "solas", es decir, sin compañía masculina. Garro expone así una fractura entre el sujeto femenino convencional y el que ella y su amiga representan al salir a la calle. Al documentar este tipo de experiencias alternas a las que otros autores escribirían después sobre ese mismo viaje a una España en guerra, considero que las memorias de viaje de Garro se instalan como pioneras en la historia literaria del viaje contemporáneo realizado por mujeres latinoamericanas.

De acuerdo con Rosi Braidotti, a diferencia de la noción de "individuo", la noción de "sujeto" se define como un proceso que sucede a partir de cambios y negociaciones constantes entre diversos 
niveles de poder y deseo, es decir, de elecciones premeditadas y de impulsos inconscientes (2011: 18). ${ }^{5}$ Esto explicaría la dislocación entre el sujeto femenino, que la conservadora sociedad franquista espera ver en Garro, y el sujeto narrado que va conformándose en la escritura de ambas. Es a través de la escritura testimonial, como forma que obliga a la memoria y la reflexión, que las autoras de crónicas o relatos de viajes cobran consciencia de su género desde una posición que las empodera y las hace distintas a lo que se espera de ellas. Ese constante proceso de construcción del yo, incluyendo una visión de futuro ineludiblemente ligado al deseo de ser otra, se puede observar en varios momentos de la experiencia de viaje de las autoras contemporáneas, sobre todo en aquellas que retan sus convicciones o costumbres relacionadas con la clase social a la que pertenecen.

Desde el siglo xIx las élites latinoamericanas solían discutir con admiración las observaciones de científicos viajeros sobre su sociedad y territorio; incluso algunos círculos habían adoptado ya la costumbre europea del Grand Tour como una forma de completar su educación, pero también de hacer negocios con otras élites. No obstante, viajar seguía siendo un acto primordialmente destinado a los hombres. El género "crónica de viaje", travel literature o travel writing, también lo era: de Herodoto a Alexander von Humboldt, Charles Darwin, Robert Louis Stevenson, Daniel Defoe, Joseph Conrad, Bruce Chatwin o Jack Kerouac, viajar y escribir sobre ello eran actividades masculinas. Las mujeres documentaban sus viajes a través de los géneros privados, como la carta y el diario, por lo general sin ambiciones de publicación. Esto explica, en parte, por

\footnotetext{
${ }^{5}$ Braidotti hace la diferencia entre dos conceptos o niveles que conforman su proyecto feminista: la subjetividad, que es un nivel consciente, en el sentido de agencia histórica y empoderamiento social y político; y la identidad, que se relaciona con las políticas de lo personal y el deseo, actuando en un nivel subconsciente (2011: 155).
} 
qué la literatura de viajes femenina -incluso ya muy entrado el siglo $\mathrm{xx}$ - ha conservado el tono intimista y privado de las confesiones, que da a veces más cuenta de los procesos identitarios de sus autoras que del acontecer histórico de su época ${ }^{6}$.

No obstante, una lectura más atenta de la escritura de mujeres latinoamericanas y sus procesos de desplazamiento permite comprobar que los viajes femeninos también han estado permeados por la ideología, la historia y la política de los espacios que documentan. Tanto Garro como las autoras latinoamericanas que analizo con mayor detalle más adelante se enfrentan en su primer gran viaje a un despertar de la consciencia de género, de clase social e ideología. A diferencia del gran viaje masculino, cuya documentación no pareciera requerir justificación para el placer, la aventura o la tradicional formación cosmopolita que el viaje ofrece, las mujeres que viajan deben justificar de alguna manera este acto.

Mientras que para las europeas y estadounidenses del siglo XIX la razón del viaje fue ejercer su oficio de educadoras, científicas o amas de casa, para las latinoamericanas que apenas empiezan a tener más libertad para viajar a mediados del siglo xx, la razón pareciera ser la ideología. El viaje femenino también será un viaje de aprendizaje, tal como lo era para los jóvenes aristócratas británicos del siglo XVIII que viajaban por el continente europeo para aprender lenguas y arte; sin embargo, este aprendizaje será distinto y tendrá otro tipo de obstáculos.

Las memorias de viaje femeninas contemporáneas muestran una triple resistencia: a obedecer el rol de género y clase asignado que implica, metafórica y literalmente, quedarse en casa; al viaje turístico burgués y al olvido de la experiencia vivida. Estos viajes son, además, una respuesta femenina a la ideología revolucionaria

${ }^{6}$ Por supuesto que las excepciones eran los textos científicos que algunas autoras lograron publicar; ver, por ejemplo, Medeiros (2019) y Gerassi-Navarro (2017). 
y libertaria que a partir de los años sesenta se viviría en la región, y en el mundo occidental en general.

Al reflexionar sobre sus propios viajes por Sudamérica, Beatriz Sarlo concluye que los viajes de los jóvenes latinoamericanos de clase media en los sesenta solían estar inspirados por una ideología de izquierda que motivaba a conocer su propio continente "a través de una experiencia directa, física” (2014: 32). Este era un viaje otro: había dejado de sońarse con destinos europeos; los viajeros ya no pertenecían exclusivamente a la clase alta, pero también se negaban a hacer el viaje masivo propio de la burguesía de la época. El viaje intelectual latinoamericano surge como una alternativa intermedia: conocerse a sí mismo significaba también conocer al otro con el que se compartía un territorio aún por explorar. ${ }^{7}$ Estas experiencias permitirían cuestionar representaciones de la identidad nacional, pero también, en el caso específico del viaje femenino, replantearse otras formas de identidad sexual y de género.

Tanto Sarlo, como Guillermoprieto y Belli declaran que sus primeros grandes viajes por países latinoamericanos fueron definitivos en su formación como sujetos políticos y feministas. Sin embargo, habrían de pasar décadas antes de que alguna de las tres pudiera sentarse a escribir sobre ellos:

no podría argumentar que estos relatos son testimonios neutrales. En todos los casos hay tres elementos que se conjugan: el sujeto que viaja; el espacio desconocido; las modificaciones de ese sujeto por haber atravesado ese espacio. Si nunca dejé de pensar en esos viajes es porque les pertenezco de una manera radical: no son

${ }^{7}$ El viaje ya estaba instituido para entonces como una práctica común entre los intelectuales latinoamericanos, aunque era mayormente masculina. Para profundizar en su historia durante el siglo xIx y principios del xx, ver Colombi (2004). 
simplemente recuerdos, sino las formas en que la experiencia me modificó en cada momento (Sarlo: 32).

En efecto, la neutralidad del registro no ficcional con todo y su convención de veracidad, llámese "memorias" o "testimonios", está en juego y reformulación constante en este tipo de relatos. Documentar el proceso no solo del viaje sino de la identidad misma de quien lo vive y lo escribe enriquece y fomenta la hibridez genérica de sus relatos. Esto lo advierte también Guillermoprieto en La Habana en un espejo, cuando confiesa que sus recuerdos de la época que relata no pueden leerse como un documento confiable:

sería absurdo afirmar que estas páginas son un relato histórico y fidedigno de mi vida en esos seis meses. Pero esto tampoco es una novela. Es la transcripción fiel de mis recuerdos, algunos borrosos, otros agujereados en la memoria al paso de los ańos, otros remendados por el tiempo y por los filtros que van interponiendo la experiencia y la distancia, y aun otros, no lo dudo, completamente inventados por ese tenaz narrador que todos llevamos dentro, que quiere que las cosas sean como nos suenan mejor y no como fueron (2017: 30-31).

Estas viajeras escriben desde un presente en que los viajes recordados las han modificado: son ya autoras reconocidas en el campo cultural de la academia, el periodismo o la literatura y ahora viajan por causas laborales más que ideológicas. Sus memorias, de hecho, obedecen a una intención de revisitar, de re-experimentar el viaje a través de la escritura desde un presente en el que el recuerdo se plasma con fines estéticos y políticos más allá del tiempo vivido. De este modo, tanto Sarlo como Guillermoprieto utilizan dispositivos de memoria, que a su vez funcionan como recursos para consolidar el pacto de veracidad con el lector, como objetos, notas 
y diarios. Asimismo, recurren a técnicas de investigación antropológica y periodística, como entrevistas a quienes las acompañaron en parte de esos viajes; también citan documentos históricos y periodísticos. Las técnicas de documentación y verificación de su propio testimonio permiten a las autoras una reflexión crítica sobre lo vivido más allá de la evocación anecdótica de sus experiencias de juventud. Esta reflexión obedece también a una voluntad o deseo por narrarse que, siguiendo a Adriana Cavarero (2006), está detrás de todo narrador de una historia de vida real. A diferencia de un narrador de ficción, el de las memorias representa a una persona de carne y hueso, un sujeto que busca a través de la escritura compartir su historia con el lector. No obstante, este sujeto narrado en los textos de carácter (auto)biográfico no puede ser sino una identidad fragmentada.

Los viajes recordados, finalmente, son un ritual de iniciación que modificará la percepción del mundo de las autoras e inciden en su propia noción de identidad. Los viajes de Sarlo definirán los intereses intelectuales de la académica que los relata, mientras que los viajes de Belli la liberarán de un estilo de vida convencional en una sociedad patriarcal y los de Guillermoprieto la convertirán eventualmente en la periodista reconocida que actualmente es.

El viaje es, por lo tanto, un momento detonante de lo que Rosi Braidotti (2011) ha llamado "subjetividad nómade" y que a lo largo del relato ofrecerá distintas construcciones del "yo". Más allá del acto literal del viaje, que también está implicado en la definición de este concepto, esta subjetividad nómade es una figuración para referirse a un ser feminista - en el sentido de tener consciencia de las diferencias sexuales, independientemente de su afiliación ideológica- que manifiesta una identidad múltiple, cambiante, abierta e interconectada con las diversas culturas en las que vive y se desplaza. No es casual, por lo tanto, que a estas autoras el viaje 
les genere reflexiones sobre su identidad, particularmente sobre la posibilidad de ser libres y abrirse al mundo.

\section{Identidad, ideología y viaje}

Sarlo, Guillermoprieto y Belli se autorrepresentan en sus memorias como mujeres de clase media, con educación universitaria y, hasta el momento del viaje representado, conservadoras ideológicamente. Desde esa posición transmiten una experiencia de viaje que evidencia el contraste entre la identidad de la narradora-protagonista del relato y los otros que encuentra a su paso. Por ejemplo, en diversas ocasiones expresan su malestar por las incomodidades de la situación del viaje y el cambio de estilo de vida que este las obliga a tener. La conflictiva conciencia de representar una identidad burguesa está presente en Alma Guillermoprieto cuando recuerda en La Habana la relación que tenía en Nueva York con Adrián, un poeta polaco con quien compartió una vivienda en decadencia: "A su lado, además, yo resultaba una mimada nińa burguesa: por las noches Adrián colocaba un litro de leche y otro de jugo de naranja en la helada repisa de la ventana y con eso desayunábamos, aunque yo hubiera preferido comprar un café caliente en la tienda de la vuelta" (2017: 1277).

Mientras que Guillermoprieto ve su clase social como un impedimento para entender otras realidades, Belli considera que moverse de manera natural en un entorno burgués le permitía destacar en sus misiones a favor de la guerrilla, puesto que recababa información para el movimiento Sandinista en las reuniones de la alta sociedad nicaragüense a las que era invitada. Belli logró incluso evadir una sospecha de su pertenencia al Frente Sandinista gracias a su apariencia; cuando su jefe en la agencia de publicidad donde trabajaba le dice que el jefe de la oficina de seguridad so- 
mocista le ha pedido que la despida por sospechas de pertenecer al Frente Sandinista, Belli le contesta:

- ¿Yo? - dijo la de cuerpo presente, con la cara de asombro más genuina del mundo-. ¿Que yo soy del Frente Sandinista? ¿Tania, la guerrillera? - Imagínense, me reí-. ¿Están locos ustedes? Mírenme bien, por favor, ¿̇se dan cuenta a quién se lo están diciendo?

Miraron mi blusa ajustada, los jeans desteñidos, la gorra coqueta de azulón colocada de medio lado sobre mi cabeza, dejando ver el pelo recogido en una cola de caballo hacia la izquierda. Sabía que me verían como lo que parecía. Una muchachita burguesa vestida a lo hippie (103-104).

Como Garro en el contexto de la guerra civil española, Guillermoprieto y Belli emprenden sus viajes sin conocer el contexto político social que las espera. Guillermoprieto empieza a leer a Ernesto "Che" Guevara hasta su llegada a Cuba; por su parte, Belli recuerda el exilio en México como un tiempo en el cual descubrió la libertad adulta. Lejos de los compromisos de la vida familiar para entonces se había divorciado y tenía dos hijas- y el constante peligro al que se exponía con sus actividades políticas clandestinas en Managua, Belli encontró en su nuevo estudio en la Ciudad de México el espacio de soledad y libertad que requería para escribir.

Las contradicciones derivadas del origen burgués de las autoras, en mezcla con su incipiente formación militante y las condiciones sociales que observan y comparten en sus viajes, provocan un aislamiento y soledad inicial. No sorprende que ambas expresen un constante deseo por volver a casa. Los obstáculos de formación e ideología que impiden al inicio comprender de manera más profunda la experiencia solo se recobrarán en su justo valor a través del recuerdo y la escritura. No obstante, las memorias aquí analizadas sí logran capturar un ambiente de época y coinciden en expresar 
las liberaciones políticas y sexuales, aunque a través del velo de la idealización romántica.

Tanto Belli como Guillermoprieto se refieren a Fidel Castro como figura de deseo. Para Guillermoprieto la conversión ideológica operó a través de los relatos de heroísmo que escuchaba y su propia experiencia una vez en Cuba:

No entendí del todo lo que decían mis compañeros acerca de la Revolución y Fidel, pero esos relatos también estaban llenos de emoción y romance. [...] la Cuba de Fidel, enfrentándose sola a todo el poderío de nuestro arrogante vecino, encarnaba una causa más que justa. [...] Y sin embargo, vivía en Nueva York, y nunca había sentido el menor deseo, la más mínima curiosidad, por viajar a Cuba (371-373).

De manera similar, en El país bajo mi piel Belli describe a Fidel Castro desde una concepción idílica de la revolución. De hecho, sus memorias sobre su participación en la guerrilla sandinista inician con el relato del primer encuentro de la autora con Castro en 1979, cuando esta era una guerrillera que tomaba un curso de armería en las instalaciones de las Fuerzas Armadas Cubanas. A diferencia de Guillermoprieto, cuando Belli viaja a Cuba ya cuenta con una trayectoria militante y una tradición política familiar que le permiten interpretar desde otro lugar su experiencia:

Era inevitable que el perfil de Fidel pusiera a girar en mi mente una confusa mezcla de imágenes del presente y el pasado. Fidel había sido el primer revolucionario del que tuve noticia en $\mathrm{mi}$ vida. Seguí su aventura rebelde como si se tratara de una serie por entregas, porque en mi casa agitó las pasiones de mis padres y sobre todo las de mi hermano Humberto, que era el líder de mis juegos infantiles. [...] Fidel era para mí el símbolo del heroísmo 
más puro y romántico. Los barbudos, jóvenes, audaces, guapos, estaban logrando en Cuba lo que ni mis primos envueltos en rebeliones ni Pedro Joaquín Chamorro, líder opositor, ni los conservadores ni nadie había logrado en Nicaragua (18-19).

La escena del encuentro personal con Castro gira no alrededor de las acciones de los personajes involucrados sino de las emociones que ella experimenta al conocerlo. Es este punto de partida del relato el que da ese tono de sensualidad que la escritura de Belli mantiene a lo largo del libro. Las memorias de Belli, al contrario de los recuerdos pasados por una intelectualización mayor de la experiencia en el caso de Guillermoprieto o Sarlo, permiten al lector entrar en un fragmento de una historia personal y política desde un ángulo íntimo, como si este estuviera invitado a actuar como testigo de una realidad velada a otros. Belli organiza sus memorias a través del lenguaje de los sentidos y comparte este mundo con el lector.

Sarlo también coincide con Belli y Guillermoprieto en ubicar sus relatos en el contexto de libertad social y sexual de la época (Strain: vi), pero en sus memorias de finales de los sesenta se puede identificar una nostalgia que ha pasado de manera más explícita o consciente por el reconocimiento de un viaje ideológico fallido. Para cuando ella empieza sus viajes por Sudamérica con dos amigas y un amigo, compañeros universitarios argentinos, el Che Guevara ya había muerto en Bolivia. La narradora reconoce que aquello que los llevó a emprender un viaje similar al de su famoso compatriota no es sino un espíritu utópico compartido:

Nuestra ideología era optimista y, como personajes de novela filosófica del siglo xvIII, nos deslizábamos interpretando todo con una especie de bonhomía radical. $\mathrm{O}$, más bien, convencidos de que el Mal no podía esconderse en ningún pliegue de esos sujetos 
a los que atribuíamos, al mismo tiempo, la bondad rousseauniana y una praxis que los llevaría, por la inercia de lo real, a convertirse en protagonistas del Gran Cambio. Todo parece singularmente inverosímil. Pero el Che Guevara, poco después, no iba a conducirse con más realismo (103).

Desde el tiempo de la narración de las memorias, Sarlo es capaz de una autocrítica que abarca también a la época; una crítica que es colectiva y que intenta explorar las razones de la desilusión ante un futuro que no sucedió como esperaban los jóvenes revolucionarios. Es hasta que intenta recordar esos viajes para escribirlos que Sarlo puede comparar su experiencia con la del líder revolucionario, en quien hasta cierto punto se refleja: "Guevara también había hecho un viaje iniciático a comienzos de la década del cincuenta, quince ańos antes que nosotros. Ese primer viaje de Guevara no se conocía en los años sesenta, ni formaba parte de la iconografía pop del héroe revolucionario. Sus evocaciones son tan ingenuas como las de cualquier mochilero de la época" (103-104).

Si bien estos "viajes iniciáticos" se ven influidos por la ideología marxista imperante en los círculos intelectuales de los jóvenes latinoamericanos de las décadas de los sesenta y setenta, para Guillermoprieto y Belli el viaje será un descubrimiento, más que reafirmación, de su postura política. Guillermoprieto viaja a Cuba para ser profesora de danza moderna y solo hasta entonces se interesa por el socialismo; Belli se involucra de manera más activa en los grupos clandestinos revolucionarios centroamericanos a partir de una relación de pareja con un líder guerrillero.

A diferencia de ellas, para la joven Sarlo la ideología no es el punto final del viaje, sino su punto de partida: "Empiristas ingenuos, pensábamos que ver era conocer. Aunque parezca una caricatura, no había mediaciones entre una teoría general del imperialismo y de las clases dominantes y las particularidades concretas 
en medio de las que avanzábamos como turistas ideológicamente automáticos: cuánta más pobreza encontrábamos, más cerca nos creíamos de la clave que perseguíamos en el viaje” (99). Sarlo y sus amigos parten de Buenos Aires bien preparados para un viaje que tiene un objetivo claro: conocer la "verdadera" Latinoamérica.

A diferencia del viaje por trabajo de Guillermoprieto o el de la necesidad de escapar de una persecución política de Belli, el de Sarlo es un viaje que se parece un poco más al viaje de exploración tradicional propio del género de la literatura de viajes. No obstante, y a pesar de que preparan sus mochilas y sus mapas al estilo que cualquier viajero europeo lo haría entonces, Sarlo y sus amigos no logran un viaje "mochilero" convencional. La elección de su destino y la intención de su viaje los lleva por rutas diferentes: su propia identidad colectiva, a medio camino entre el viajero explorador europeo y el peregrino religioso indígena, será lo que les permita una experiencia viajera tan singular como también lo es la de Belli y Guillermoprieto. Con todo, el efecto del viaje de Sarlo es inversamente proporcional al de Guillermoprieto y Belli, puesto que la realidad se impone como contraria al mapa imaginado a través del filtro ideológico:

Nosotros no éramos turistas ni antropólogos. Hacíamos un viaje latinoamericano de aprendizaje, el grand-tour ideológico por territorios empobrecidos y explotados por quienes nosotros (y miles de jóvenes) denominábamos las oligarquías locales y el imperialismo. Viajábamos para comprobar lecturas, como si dar vueltas por la realidad pudiera producir un documento probatorio, sin más. No buscábamos ni exotismo, ni pintoresquismo sino un tiempo futuro y anunciado (104). 


\section{Una "zona de contacto" revisitada}

La rareza, excentricidad o hasta peligro que implica el viaje femenino es una constante en los relatos de autoras latinoamericanas viajando dentro o fuera de sus países y que atraviesa distintas épocas. En Viajes: De la Amazonía a las Malvinas, Sarlo recuerda cómo, a principios de los sesenta, ella y tres amigos universitarios (dos mujeres y un hombre) llegaron a la cordillera de los Andes. Buscando dónde pasar la noche, conocieron a la maestra de una escuela rural, que tenía su misma edad y vivía sola en la escuela. Los viajeros se quedaron unos días conviviendo con la maestra y sus alumnos. Sarlo describe este tiempo idílicamente, puesto que encarnaba sus aspiraciones de ayudar a forjar comunidades solidarias como aquella para toda América Latina: "Buscábamos un continente en curso de transformación: había que viajar por América Latina porque el desplazamiento nos llevaría hacia formas semiocultas o más o menos visibles de futuro" (32). Su futuro, sin embargo, no fue el mismo que para la maestra rural. Años después, Sarlo se enteró que la maestra había sido asaltada por un hombre y se encontraba malherida. Aquel contexto idílico también era uno de pobreza, marginación y vulnerabilidad, un presente sin el futuro que ellas imaginaron. Sarlo llama a este tipo de escenas en sus viajes un "salto de programa", es decir, una realidad que irrumpe de golpe y cambia el imaginario.

Este salto al programa de Sarlo podría considerarse una versión actualizada y latinoamericanizada del tipo de encuentro al que alude Mary Louise Pratt al acuñar el término "zona de contacto" para su estudio sobre la literatura de viajeros europeos a América y otras zonas coloniales durante el siglo xIx. Para Pratt, el viaje hace posible la creación de un espacio de "encuentros imperiales" (1992: 8), es decir, una zona de intersección o contacto entre personas histórica y geográficamente distintas. En la concepción 
de Pratt, no obstante, la zona de contacto requiere un encuentro entre sujetos culturalmente distintos; para Sarlo, estas diferencias entre el viajero latinoamericano y el otro, ese habitante de realidades distintas a las de la narradora, no necesariamente pasan por la historia o la geografía, sino por las diferencias de clase, raza y, habría que añadir, de género. Saltarse el programa significa buscar conscientemente ese encuentro con el otro, no con la intención de colonizarlo, de demostrar su hegemonía, sino de reconocerse como cohabitantes de un espacio determinado, más allá de las diferencias. De esta manera, al relatar sus propios encuentros con el otro en el contexto revolucionario latinoamericano de los sesenta, Sarlo reactualiza, en toda su complejidad e inequidad, el encuentro entre el viajero conquistador-explorador-turista y el habitante de zonas marginales, exóticas o remotas, que históricamente ha sufrido los efectos de la colonización occidental.

No se puede ignorar el papel que la ideología juega en estos encuentros entre dos "otros", puesto que el sujeto que viaja y escribe ya no es un sujeto que observa desde su poder imperial. Este nuevo viajero se siente más cercano, por compartir tiempo y espacio, a ese otro que describe. La relación no deja de ser compleja y Sarlo toma distancia (auto)crítica para asumir un punto medio desde el cual sigue siendo consciente de las diferencias: "Practicábamos una especie de relativismo cultural espontáneo, sostenido en la admiración folklórica por lo diferente, el respeto a la gente pobre y un latinoamericanismo sostenido como deber ideológico. Preguntar por 'esos indios' nos habría resultado de una violencia imposible para el progresismo candoroso que era nuestra ideología" (130). Sin embargo, en varias escenas de los viajes que recuerda Sarlo la diferencia en el color de piel y en su apariencia la harán sentir distinta y su identidad latinoamericana será constantemente cuestionada.

Desde el presente de la mujer adulta, transformada en una académica y escritora con un bagaje cultural superior al de la joven 
protagonista de sus relatos, la narradora advierte de la inocencia de esos viajeros, pero insiste en el valor de un viaje que se deslindaba del turístico: "Someterse a la experiencia aurática era el trip dentro de nuestros viajes. Hoy puedo frasearlo. No habría podido entonces. No habíamos leído a Benjamin pero estábamos sometidos a una metafísica de la presencia, desplazándonos en el espacio con la ilusión de realizar otro viaje, paralelo, en la historia de América” (131). Al desplazarse por territorios que antes fueron recorridos por los viajeros conquistadores y que entonces seguían sin ser parte de las rutas del turismo masivo, Sarlo y sus amigos se sitúan en una zona intermedia para la que aún no había categoría posible. Son latinoamericanos, sí, pero su clase y su apariencia física marcan diferencias insalvables respecto a los otros con quienes se enfrentan y que son también latinoamericanos. El viaje de Sarlo y sus amigos es utópico también por estas diferencias que impiden un encuentro horizontal, pese a las buenas intenciones de los viajeros. Ellos no son migrantes ni peregrinos, aunque justo terminen contando que lo son cuando se encuentran gente en su camino que los cuestiona, pues ¿qué otra razón podía haber en los años sesenta para que cuatro jóvenes burgueses argentinos desearan visitar territorios alejados de las grandes urbes, a través de caminos peligrosos y pasando incomodidades de todo tipo?

\section{Conclusiones}

En The Golden Notebook (1962), la escritora británica nacida en África Doris Lessing describe la situación para una mujer que elige vivir libremente a mediados del siglo xx en Londres: lejos de sentirse feliz por lograr una vida independiente a un esposo o familia, la protagonista de su novela descubre una contradicción entre sus acciones y sus sentimientos. La protagonista de la novela, Anna, es una intelectual excomunista que se mantiene de su escritura, vive 
sola con su hija en un departamento londinense, pero no puede mantener relaciones amorosas sanas; concluye que son los sentimientos "femeninos" los que son incongruentes con el tipo de vida de la mujer moderna. Anna ha logrado el ideal propuesto por Virginia Woolf para su género: dinero y una habitación propia, es decir, independencia. Sin embargo, al no controlar sus deseos, la protagonista entra en una crisis que la llevará a cuestionar el papel de la mujer moderna. Esta contradicción seguirá presente a lo largo del siglo xx y hasta el inicio del xxI en las mujeres latinoamericanas, quienes a penas hacia mediados de los setenta iniciarían una vida libre e independiente como la ya anunciada por Woolf en los treinta y luego expuesta en su modo más complejo por Lessing en los cincuenta.

Desde América Latina, autoras como Sarlo, Belli y Guillermoprieto también experimentaron la libertad y las contradicciones de vida de una mujer moderna. Emancipadas del ámbito familiar vivieron con una libertad excepcional con respecto a las mujeres de su época. Aunque divididas entre las labores domésticas y su rol de esposas o madres, su género no les impidió viajar e incluso vivir temporadas lejos de casa. Explorar este tipo de escrituras dentro del marco de narrativas documentales o de no ficción, en especial el género de la crónica, es de utilidad para establecer relaciones entre los conceptos de género, clase social y cultura.

Las ideas delineadas en este artículo intentan contribuir al debate sobre la construcción de identidades y futuros posibles para la mujer en América Latina, a la vez que insertar a las autoras estudiadas en una genealogía alterna de la historia de la literatura femenina latinoamericana y, más ampliamente, occidental. Además, este tipo de escritura ofrece una ventana a la intimidad de la vida cotidiana desde perspectivas que pocas veces la ficción y las crónicas de viajes tradicionales pueden ofrecer para el caso de las mujeres. Estas narrativas demuestran además la importancia que tienen los 
géneros de no ficción no solo como fuentes de información para la historia literaria sino como formas de registro del contexto social e intelectual de una época y de las condiciones de formación de la personalidad femenina.

Como el narrador descrito por Walter Benjamin (1999), estas autoras salen de su comunidad, pero regresan para compartir aunque solo sea varias décadas después- las historias de la gente que han conocido. Las narradoras exponen a través de sus memorias su ser vulnerable y único. Su historia es una confesión al lector que da testimonio no solo de su propia vida sino de todos aquellos que ha encontrado en su camino.

La subjetividad nómade que estas autoras representan se convierte en una figuración para referirse a un ser feminista que manifiesta una identidad múltiple, cambiante, abierta e interconectada con las diversas culturas en las que ellas viven, se desplazan y proyectan diversas formas de ser y estar. Los relatos de viaje femeninos como los analizadas aquí bajo la categoría de "memorias" modifican también la definición etimológica del término "crónica".

Más allá del viaje femenino como acto de liberación en sí mismo, propongo una lectura de estas narrativas del yo como un acto de oscilación entre pasado, presente y futuro. A medida que otros viajes se acumulan en sus relatos, las autoras estrechan la relación entre experiencia de viaje y autoconsciencia de la identidad como proceso. La palabra escrita se convierte entonces en su herramienta de re-creación de un mundo y proyección de otros mundos posibles a través del recuerdo y la imaginación. 


\section{Bibliografía}

Braidotti, Rosi, 2011, Nomadic Subjects. Embodiment and Sexual Difference in Contemporary Feminist Theory, Columbia University Press, Nueva York.

Broome Saunders, Clare (ed.), 2014, Women, Travel Writing, and Truth, Routledge, Nueva York.

Benjamin, Walter, 1999, "The Storyteller. Reflections on the Works of Nikolai Leskov", en Hannah Arendt (ed.), Illuminations, Harry Zorn (trad.), Pimlico, Londres, pp. 83-107.

Carrizo Rueda, Sofía, 1997, Poética del relato de viajes, Rechenberger, Kassel.

Cavarero, Adriana, 2006, Relating Narratives. Storytelling and selfhood, Paul A. Kottman (trad.), Routledge, Nueva York.

Colombi, Beatriz (coord.), 2016, Viajes, desplazamientos e interacciones culturales en la literatura latinoamericana. De la conquista a la modernidad, Biblos, Buenos Aires.

Colombi, Beatriz, 2004, Viaje intelectual. Migraciones y desplazamientos en América Latina 1880-1915, Beatriz Viterbo, Rosario.

Earle, Rebecca, 2016, "Introduction: letters, writers and the historian", en Rebecca Earle (ed.), Epistolary Selves: Letters and Letter-Writers, 1600-1945, Routledge, Londres, pp. 1-12.

Garro, Elena, 2011, Memorias de España 1937, Salto de página, Madrid

Gerassi-Navarro, Nina, 2017, Women, Travel, and Science in Nineteenth-Century Americas. The Politics of Observation, Palgrave Macmillan, Cham.

Guillermoprieto, Alma, 2017, La Habana en un espejo, Penguin Random House [edición electrónica en Kindle]. 
Guzmán Rubio, Federico, 2011, “Tipología del relato de viajes en la literatura hispanoamericana: definiciones y desarrollo", Revista de Literatura, enero-junio, vol. LXXIII, núm. 145, pp. 111-130.

Hahner, June E (ed.), 1998, Women's through Women's Eyes. Latin American Women in Nineteenth-Century Travel Accounts, SR Books, Wilmington.

Holland, Patrick y Graham Huggan, 2000, Tourists with Typewriters. Critical Reflections on Contemporary Travel, University of Michigan Press, Ann Arbor.

Lindsay, Claire, 2010, Contemporary Travel Writing of Latin America, Routledge, Londres.

Medeiros, Michelle, 2019, Gender, Science and Authority in Women's Travel Writing. Literary Perspectives on the Discourse of Natural History, Lexington Books, Lanham.

Pitman, Thea, 2009, "Postcolonial Compañeras? The Desire for a Reciprocal Gaze in Two Mexican Women's Accounts of Africa”, Journal of Transatlantic Studies, núm. 7, pp. 376-88.

Pratt, Mary Louise, 1992, Imperial Eyes: Travel Writing and Transculturation, Routledge, Londres.

Strain, Christopher B., 2017, The Long Sixties. America, 19551973, Wiley Blackwell, Oxford.

Villoro, Juan, 2020, Palmeras de la brisa rápida, Almadía, Oaxaca de Juárez. 